\title{
MAJOR TRENDS IN EUROPEAN MEDIA COVERAGE OF THE MIGRATION CRISIS 2015-2016
}

\author{
Albina R. Shakurova ${ }^{1}$ \\ Rezida V. Dautova ${ }^{2}$
}

\begin{abstract}
This article is devoted to the problem of the migration crisis of 20152016. in Europe and the reflection of this problem in media texts. The current stage of development of society is characterized by the increasing influence

the report "The European migration crisis and the media. A cross-European press content analysis". Migrants and refugees are a vulnerable minority that can easily suffer from the internal problems of the host country.
\end{abstract} of journalism on all spheres of life and human activity. The greatest influence in this context is television, which for many Russian citizens is the most accessible source of information. Analyzing the state of the participants of the modern migration crisis according to reports in the Russian media, we came to the conclusion that it is necessary to turn to the works of European researchers who see the situation from the inside. We studied media stereotypes about migrants and refugees, presented in a report by the international group of researchers from the Department of Media and Communications of the London School of Economics and Political Science and published in 2017

Keywords: media stereotype, Europe, migration crisis, refugees.

\section{Introduction}

Gabriela Giacomella, in her study Media and Migration, emphasizes that every media outlet, to varying degrees, is "a victim of the temptation to fan the news and portray a sensational, simplified version of the story." In this way, information is provided to the audience that begins with resonant negative messages, and the stereotypical image of migrants is identified with disturbing concepts such as emergency, segregation, and cultural differences. Moreover, it is important not so much a

\footnotetext{
${ }^{1}$ Kazan Federal University. Email: veiy@ mail.ru. Tel: 89510618591

${ }^{2}$ Kazan Federal University. Email: veiy@ mail.ru. Tel: 89510618591
} 
complete listing and disclosure of the content of all existing stereotypes as the context and direction of the development of stereotyping of images of migrants and refugees in European media reality. There is an obvious need to study the degree to which the topic is represented in the works of direct witnesses of the events, how the topic of migration processes developed in the European media. Thus, we can answer the question whether the representation of the topic of the European migration crisis in the Russian media is a continuation of the European discourse, or is this topic developing independently in the domestic media space. Perhaps the Russian media oppose the European.

\section{Methods}

The problem of the representation of migration processes in the media is receiving much attention in Europe. In 2016, a symposium entitled "Refugees and Migrants, the inconvenient truths - Journalism against bias and stereotypes" ("Refugees and Migrants, Uncomfortable Truths: Journalism Against Bias and Stereotypes") was held, dedicated to the work of various media in sanctifying the
European migration crisis. In November of the same year, a roundtable was held on Europe's Migration and Security Nexus: The Role Of The EU And The UN (Migration in Europe and Security: the Role of the EU and the UN). And discussions, attempts to solve the problems arising in connection with migration processes in Europe did not stop. 2017 Forum “Towards a Global Social Contract on Migration and Development" ("Towards a Global Social Compact on Migration and Development") and the round table "The European Migration, Border and Security Roundtable 2018" of borders and security in Europe - 2018") are also devoted to the topics of adaptation of migrants. Mention of such events is really a lot.

A special approach of Europeans to the problem of migrants is reflected in a large number of studies devoted to this problem.

We turned to the original texts of two foreign reports on the results of monitoring European media for 20152016. An international group of researchers from the Department of Media and Communications of the London School of Economics and 
Political Science published a report in 2017, "The European migration crisis and the media. A cross-European press content analysis" ("European Migration Crisis and the Media. Cross-European Press Content Analysis").

In their work, Lily Chuliaraki, Miria Gheorghiu, Rafal Zaborovsky conclude that high-quality European media played an important role in framing the problem and in assessing the causes and consequences of the "migration crisis". The same group of scientists prepared an interim report entitled "Council of Europe report: Media coverage of the "refugee crisis": A cross-European perspective" ("Council of Europe report: media coverage of the "refugee crisis: a crossEuropean perspective"), made for the Council of Europe and containing specific recommendations on working with the media.

The most significant drawback of these works is the choice of the empirical base, which is represented only by the press. Television was not covered in the report. At the same time, the authors themselves note that the quality of publications in print media is affected by high competition with electronic media and social networks. This, however, does not diminish the conclusions drawn by this group of scientists.

\section{Results And Discussion}

Among the European public, there is a perception that the media are dominated by weak vocabulary, political bias, incitement to hatred, stereotypes and social exclusion of refugees and migrants, which leads to an atmosphere of intolerance, xenophobia and racism. That is why, in our opinion, migrants and refugees are perceived as a vulnerable minority. And this group of people can easily suffer from the problems of the host society: social and economic decline, crime and unemployment, pressure on social security services and insecurity.

In our opinion, the special attitude to the responsibility of the media to society that has developed in European society is revealed precisely in the way politicians and public figures in the European Union seek to attract the press, radio, television and online publications to adapt refugees and create their positive image. In 2015, journalists recorded the largest movement of people 
across borders, publishing many articles about it daily. The events, which soon became widely called the European "refugee crisis" or the European "migration crisis", required attention and action on the part of governments, politicians and the European public.

We emphasize that in the European consciousness, television, radio and the press are still key and reliable sources of information for officials and the public, allowing them to stay up to date and take action promptly. It seems to us that in this case their role was even more important than usual. First, the scale and speed of events in the second half of 2015 meant that the public and policy makers relied on indirect information to understand local events. Secondly, the lack of acquaintance with the new arrivals, their history and the reasons for their difficult situation meant that many Europeans depended exclusively on the media to understand what was happening.

And this means that the activities of journalists can and should contribute to the construction of positive stereotypes about migrants in Europe. The work of Western media scholars also highlights the problem of the dissemination of stereotypes about migrants, refugees and other minorities in the media, which can lead to prejudice and discrimination of certain representatives of such groups and the rejection of cultural diversity in general. European politicians and media regulators are also concerned about this issue. Our attention was especially drawn to the fact that in the European Union the practice of creating recommendations for journalists on how and in which case it is necessary to act, how and how to cover a particular problem is widespread. For example, the Office of the United Nations High Commissioner for Refugees, in a report based on collaboration with the National Union of Journalists of Great Britain and the Irish Refugee Council, provides practical guidelines for interviewing and interviewing refugees and asylum seekers, and a glossary with appropriate terminology for reliable reporting.

One of the first cases that attracted significant public and transnational political and media attention was related to the so-called "Leveson Report" - a judicial public investigation of the culture, practice and ethics of the British press after the News 
International telephone hacking scandal, chaired by Lord Justice Leveson . During 2011, a series of public hearings was held. Inquiry published the Leveson Report in November 2012, which examined the general culture and ethics of the British media, and made recommendations for the creation of a new independent body to replace the existing Press Complaints Commission. In his report, Lord Leveson noted that "some newspapers have always clear ideas about the harm caused by migrants and / or asylum seekers (often mixing them up), tailoring the facts to their vision." Note that the Commission on complaints about the press after this was dissolved.

We have studied the recommendations of the European Commission against racism and intolerance. The recommendations state that inciting hatred involves advocating, encouraging, or inciting libel, hatred, or insulting a person or group of people, as well as any harassment, insult, negative stereotyping, stigmatization or threat to such a person or persons, as well as any justification for all these forms of expression based on personal characteristics or status, which include race, color, language, religion or belief, citizenship or nationality or ethnic origin, and pedigree, age, and disability, gender, gender, gender identity and sexual orientation."

This naturally raised our question: how sensitive is journalistic practice in covering the refugee crisis to these forms of discrimination? To what discursive model of representation of migratory processes are European journalists contacting? The answer to these questions was the appeal to the indicated materials.

\section{Summary}

A report by Lily Chuliaraki, Miriya Gheorghiu and Rafale Zaborowski offers a cross-European perspective. It mainly relies on an analysis of European influential press in eight Council of Europe member states, as well as two major Arabic newspapers. The report consists of three main sections: politics and the media context of media coverage; key elements of press coverage in Europe in eight countries (Czech Republic, France, Germany, Greece, Hungary, Ireland, Serbia and the 
United Kingdom); problems of media practice and recommendations.

The authors note that the press, when covering migration processes, was biased. Firstly, the fact that in the early periods of the crisis, when causal relationships could not be established between the plight of migrants and the well-being of European countries, most journalistic stories about refugees mentioned possible risks for European societies, which is well demonstrated by the general narrative. built by the European press: anxiety about undesirable consequences.

Secondly, the negative consequences formulated in the press rarely emphasized moral justification and were mainly geopolitical, economic or cultural in nature. On the other hand, when positive consequences were mentioned, they were formulated primarily as a moral imperative of empathy or even solidarity. Thus, the direction of the story connects the negative consequences with real, tangible events in European countries, while very few positive aspects are presented in the materials on the moral component of assistance to refugees.
Thirdly, specific types of negative consequences show fluctuations in the narrative of Europeans throughout 2015. This means the European press is moving toward securitization discourses after the Paris attacks: refugees are shown in the context of the geopolitical dangers that they bring with them.

Fourth, the geographical location of countries is strongly correlated with the types of narratives in the local press.

Another conclusion drawn by European studies concerns the image of the refugees themselves. Although the European press talks a lot about refugees and migrants, their descriptions are very limited. In the press, refugees were mostly called citizens of a certain country $(62 \%$ of the articles in the sample). Only $35 \%$ of the articles distinguish between men and women among refugees and less than a third of the articles mention refugees as people of a certain age group, only $16 \%$ of the materials mention the names of refugees, and $7 \%$ include their professions.

Thus, refugees appear in these materials as an anonymous unqualified group. They are "different" to the 
intended audience, and this limited characterization creates discourse around the refugee crisis for both the European audience and stakeholders. In an indirect narrative, without individual characteristics, it is understood that refugees are unsuitable for European countries, cause little sympathy and arouse suspicion.

In all countries analyzed by a group of European researchers, interviews by representatives of national governments, other governments, or European politicians were featured in articles significantly more often than the voices of asylum seekers. Moreover, the opinions of European citizens are presented even less than the opinions of refugees. Finally, refugee women are virtually invisible to European journalists. Women are rarely quoted, and descriptions of arriving men and children dominate.

In our opinion, the conclusions made by researchers from the Department of Media and Communications of the London School of Economics and Political Science indicate a gradually increasing representation of the problematic narrative of the events of the migration crisis in the media, which is also confirmed by other researchers. The report pays a lot of attention to refugees and the reasons for seeking asylum in Europe. However, the authors of the report themselves note that the European press has focused on the negative consequences of the arrival of refugees.

In accordance with the growing militaristic structure of media discourse, the peak of the migrant crisis led to a gradual change in narratives in the media - from an emotional, humane narrative to an insensitive, protective frame. L. Chuliaraki, M. Georgiou, and R. Zaborowski note that these results differ in different countries, and that there is a west-east structure: the largest gap between the emphasis on the feelings of one's own citizens compared to the feelings of refugees was found in western countries (France, Ireland, Czech Republic, Germany), and in eastern countries (Greece, Serbia, as well as the Arabic-language press), media texts were more balanced.

Although geographical proximity to the borders of Southeastern Europe is becoming an important factor in the report, the correlation is not direct. We noted for ourselves the existence of 
significant differences between the "countries of the first contact", since there are differences between the countries of Europe. For a more complete understanding of these complex relations, it is necessary to take into account a number of additional factors, which include not only the socioeconomic and political context of the country in question, but also the culture of the press, legal regulation of the media, an ideological approach, orientation of the press, media literacy of the population and the degree of freedom of the media in each country.

In our opinion, the choice of $\mathrm{L}$. Chuliaraki, M. Georgiou, and R. Zaborowski of the press of only eight countries of the European Union for a study that claims to reflect the crossEuropean perspective of representing a problematic topic is quite controversial. Despite the processes of globalization, the lack of tight borders within the European Union, European identity and worldview are not monolithic. Perhaps a more global study is proposed by this group of scientists in the future, although this is not obvious from the report.

An analysis of German federal print media and their online versions by
German scholars also notes features of the local media. The pages of the Spiegel magazine feature photo reports from rallies in large German cities (Berlin, Hamburg, Munich, Stuttgart, etc.). Dissatisfied German citizens become radicals. On one of the posters of the demonstration in Berlin the inscription "Shut your throat, Merkel." What is this if not "hostile language"? Doubts about the correctness of the chancellor's policy regarding the migration issue in Germany are demonstrated by the interrogative cover of the Fokus magazine with a parody of the chancellor's famous quote: "Will she cope?" ("Schaft sie das?”).

Another European study by M. Berry, I. Garcia-Blanco and C. Moore notes that the media in Sweden and Germany overwhelmingly use the term "refugee" and, to a lesser extent, "asylum seeker" and "migrant". In Swedish newspapers, there was a large concentration of attention on rescue operations, mortality statistics, political debates and the role of smugglers in migration processes, and humanitarian issues and the plight of refugees and migrants were discussed. M. Berry, I. Garcia-Blanco, and C. Moore also 
propose dividing the migration crisis into national and transnational problems.

\section{Conclusions}

Thus, the European media is one of the parties, it is a participant in modern migration processes in Europe. In our work, we turned to the crossEuropean analysis carried out by L. Chuliaraki, M. Georgiou and R. Zaborowski, and also provide extracts from the research of M. Berry, I. GarciaBlanco and K. Mura. Their work serves as an excellent guide for our research. However, we noted some features of the study of L. Chuliaraki, M. Georgiu and R. Zaborovsky, which we consider to be shortcomings. This appeal is only to the press as an empirical basis, despite the fact that the study was initially presented as media monitoring and the researchers themselves note the strong competition of the press with electronic media. Scientists also turned to the press in 8 countries, while their work involves a cross-European approach. Moreover, the choice of countries is not justified.

\section{Acknowledgements}

The work is performed according to the Russian Government
Kazan Federal University.

\section{Bibliography}

Jacomella, G. Media and migrations: press narrative and country politics in three European countries', Fellowship Papers, Reuters Institute, University of Oxford. [Electronic resource] // 2010. Access mode:

https://reutersinstitute.politics.ox.ac.uk/ our-research/media-and-migrationspress-narrative-and-country-politics$\underline{\text { threeeuropean-countries }}$

ECRI general policy recommendation no. 15 on combating hate speech [Electronic resource]// Access mode: https://rm.coe.int/ecri-general-policyrecommendation-no-15-on-combatinghate-speech/16808b5b01

Bijak J., The European Refugee CriSiS: A Reflection. Population Europe, 2016. [Electronic resource]// Access mode: http://www.populationeurope.eu/Statement/european-refugee$\underline{\text { criSiS-reflection }}$ 
Amann, M., Baumgärtner, M., Feldenkirchen, M., Knobbe, M., Müller, A-K., Neubacher, A. And Schindler, J. Aufstand der Ängstlichen [=Riot of fearful], [Electronic resource]// Access mode:

http://www.spiegel.de/spiegel/print/d140390005.html., accessed 29.01.2016. (In Germ.).

Merkels Flüchtlinge und Deutschlands Grenze [=Merkel refugees and Germany border],

[Electronic resource]// Access mode: http://www.focus.de/politik/focus-titelmerkels-fluechtlinge-und-deutschlandsgrenzen_id_4958093.html, accessed 02.01.2016. (In Germ.).

Berry M., Garcia-Blanco I., Moore K. Press coverage of the refugee and migrant crisisin the EU [Electronic resource]// Access mode: A content analysis of five European countries. Cardiff: Cardiff School of Journalism, Media and Cultural Studies, 2016. 276 p.

URL:
Chakvetadze L.G, Dautova R.V, Shakurova A.R. Gender stereotypes, mass media and migrants / Chakvetadze L.G, Dautova R.V, Shakurova A.R.//Journal of Organizational Culture, Communications and Conflict. - 2016. Vol.20, Is.SpecialIssue2. - P.39-45.

Shakurova A.R. Psychological mechanisms of stereotype development on television (on the example of the European migration crisis of 20152016)/ A.R. Shakurova // National Academy of Managerial Staff of Culture and Arts Herald. -017. - No. 4 (1). -C. 338-341.

Olshansky, D.V. Political PR / D.V. Olshansky - St. Petersburg: Peter, 2003 $544 \mathrm{p}$.

Pipia, K.D. Echo of the European Migration Crisis: "alien" refugees and "their" migrants as perceived by Russians in 2015-2016 / K.D. Pipia // Bulletin of public opinion. Data. Analysis. Discussions. - 2016. - No. 3-4 (123) - p. 160-169

http://orca.cf.ac.uk/87078/1/UNHCR\%20FINAL\%20REPORT.pdf 